\title{
Coletivos de Trabalho, Inserção e Formação: O Caso dos Juízes do Trabalho
}

\author{
Collectives of Labor, Insertion and Education: \\ The Case of the Labor Judges \\ Colectivos de Trabajo, Inserción y Formación: \\ El Caso de los Jueces del Trabajo
}
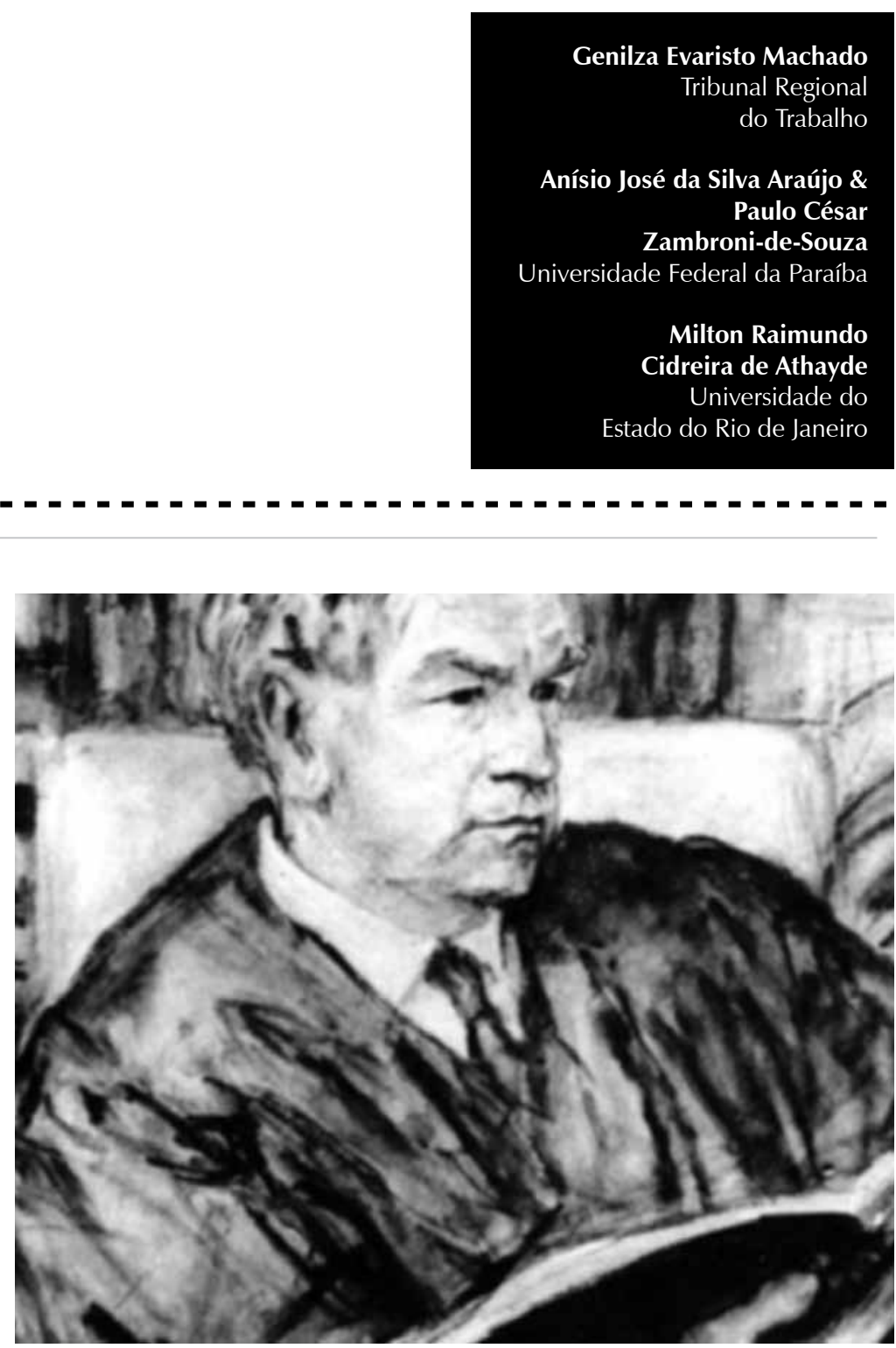
Resumo: O artigo propõe-se a refletir sobre os processos de inserção profissional e formação continuada de juízes do trabalho de um Tribunal localizado na Região Norte do Brasil, colocando em destaque, a partir da contribuição de algumas abordagens clínicas do trabalho, a função que os coletivos de trabalho podem desempenhar nesses processos. O artigo baseia-se em pesquisa qualitativa, da qual participaram treze juízes, por meio de entrevistas individuais semiestruturadas, examinadas pela técnica da análise de conteúdo temática. Os resultados evidenciam que a inserção na magistratura é marcada por dúvidas, receios, medos e inseguranças, e que sua formação continuada se vê prejudicada pelo aumento do volume de tarefas que consomem a jornada de trabalho, avançando em uma faixa do tempo extratrabalho. Tais dificuldades são enfrentadas na solidão ou, quando muito, com o apoio de um círculo muito restrito de pares. Sugere-se que as dificuldades seriam mais bem geridas caso os coletivos de trabalho se mostrassem mais receptivos.

Palavras-chave: Psicologia organizacional. Trabalho. Formação profissional. Redes sociais.

Abstract: This paper is meant to discuss the processes of insertion and professional education of labor judges in the North Region of Brazil, focusing on the role that labor collectives may play in these processes. The paper is based on qualitative research conducted with 13 judges by the means of semi-structured interviews, assessed with the help of the technical analysis of their thematic contents. The results obtained show that the insertion in the law court is surrounded by questions, fear and vacillation. After all, their continuing education is harmed by the great amount of work, which consumes their labor-time. Such difficulties are either lonely faced or with the help of a very restrict number of colleagues. This work shows that this problem would be better managed if the collectives of labor were friendly with their new members.

Keywords: Organization psychology. Work. Professional education. Social networks.

Resumen: El artículo se propone reflejar sobre los procesos de inserción profesional y formación continuada de jueces del trabajo de un Tribunal localizado en la Región Norte del Brasil, colocando en destaque, a partir de la contribución de algunos abordajes clínicos del trabajo, la función que los colectivos de trabajo pueden desempeñar en esos procesos. El artículo se basa en pesquisa cualitativa, de la cual participaron trece jueces, por medio de entrevistas individuales semi-estructuradas, examinadas por la técnica del análisis de contenido temático. Los resultados evidencian que la inserción en la magistratura está marcada por dudas, recelos, miedos e inseguridades, y que su formación continuada se ve perjudicada por el aumento del volumen de tareas que consumen la jornada de trabajo, avanzando en una franja del tiempo extratrabajo. Tales dificultades son enfrentadas en la soledad o, cuando mucho, con el apoyo de un círculo muy restricto de pares. Se sugiere que las dificultades serían mejor regidas en caso de que los colectivos de trabajo se mostrasen más receptivos.

Palabras clave: Psicología organizacional. Trabajo. Formación profesional. Redes sociales.

Este artigo tem dois principais objetivos: por um lado, compreender quais as dificuldades que os juízes do trabalho enfrentam ao ingressar na magistratura e como fazem a gestão dessas dificuldades no seu dia a dia. Evidenciou-se que os iniciantes no cargo enfrentam grandes obstáculos para realizar o seu trabalho ao constatarem que seu conhecimento teórico e prático é insuficiente para executar sua atividade de forma satisfatória, que se torna para eles fonte de insegurança e ansiedade. Sustentase que essa inserção poderia ser mais bem encaminhada com a incorporação desses novatos pelos coletivos de ofício pertinentes, o que lhes permitiria melhor domínio das regras de trabalho, de cuidado do ofício e da saúde dos operadores.
Por outro lado, procurou-se investigar as práticas de formação continuada, formais e informais, operadas pelos juízes do trabalho. Apesar da existência de um consenso sobre a necessidade de maior investimento em formação continuada, esta ainda se encontra distante das expectativas, em processo de estruturação. Tal condição exige dos juízes do trabalho esforços compensatórios para se manterem atualizados e assim poderem oferecer respostas mais adequadas aos processos que lhes chegam às mãos. Apesar disso, é o volume de tarefas que tem se apresentado, em sua experiência, como o grande empecilho a um investimento maior por parte dos juízes na necessária formação continuada. 
Este artigo explora, em um primeiro tópico, os novos contornos da magistratura, apresentando brevemente o que representou para a Justiça do Trabalho a promulgação da Emenda Constitucional no 45. Na sequência, apresentam-se as opções teóricas dos autores no que tange à discussão sobre a dimensão coletiva do trabalho, aspecto que sobressaiu dos dados empíricos e que motivou a confecção deste artigo. As seções seguintes são dedicadas à explanação do método utilizado, à discussão dos resultados, e finalizam com algumas considerações conclusivas.

\section{Mudanças na magistratura e as novas demandas sobre a Justiça do Trabalho}

Alguns autores apontam uma série de mudanças que vêm alterando o perfil da magistratura. Prado (2005), por exemplo, embora considere que a imagem ainda predominante na sociedade com relação ao magistrado brasileiro seja a de um personagem anacrônico, rígido e distante, reconhece que cada vez mais os juízes vêm atuando como formadores de opinião junto aos seus pares e a outros operadores jurídicos. Segundo essa autora, a clássica figura do magistrado neutro, rígido cumpridor da lei e distante das partes e da sociedade está em processo de superação, com muitos juízes adotando posturas críticas em relação à própria atuação e tornando-se conscientes de que o Judiciário precisa se renovar.

Nessa mesma direção, Sadek (2006) revela que poucos profissionais passaram por tantas modificações nos últimos anos quanto os magistrados. Eles têm sido convocados para se pronunciar sobre diversos temas, ocupando espaços na arena pública e desempenhando papéis diversos da clássica imagem de discrição e de impessoalidade.
A Emenda Constitucional no 45/2004 ampliou de forma considerável a competência da Justiça do Trabalho, pois, enquanto a Constituição Federal de 1988, em seu art. 14, atribuía à Justiça do Trabalho a conciliação e o julgamento dos conflitos entre trabalhadores e empregadores resultantes da relação de emprego, o novo texto constitucional substitui a expressão "relação de emprego" por "relação de trabalho", fazendo com que parte das lides julgadas pela Justiça Federal e pela Justiça Comum fosse assumida pela Justiça do Trabalho (Schiavi, 2006), o que acarretou aumento na demanda trabalhista e mudanças nos requisitos de inserção e formação continuada.

Além disso, tal emenda, reconhecendo a importância da experiência na área jurídica para o exercício da magistratura, passou a fazer as seguintes exigências para inserção na carreira: experiência mínima de três anos em atividade jurídica e participação em cursos de preparação e aperfeiçoamento de magistrados como etapa obrigatória do processo de vitaliciamento e como critério para promoção por merecimento.

Ao mesmo tempo em que se observam essas mudanças no perfil da magistratura, é preciso reconhecer que o ato de julgar envolve tensão e desgaste emocional que estão diretamente ligados à saúde e à qualidade de vida do magistrado, pois a sentença proferida pelo juiz produz efeitos não apenas nas partes envolvidas mas também na sociedade.

Segundo Ribeiro (2005), juízes que participaram de um estudo realizado no Tribunal de Justiça de Santa Catarina relataram ser exaustivo o trabalho da magistratura, por envolver pressões, volume crescente de processos e condições materiais insatisfatórias para a realização do ofício. Relataram, ainda, sofrimento psíquico causado pela sensação de frustração e impotência diante do aumento 
Para Clot (2008),

o coletivo de

trabalho tem uma

função primordial

na manutenção

e no

desenvolvimento

de um ofício,

sendo condição

para que alguém

consiga realizar

bem seu trabalho

e aperfeiçoar seu estilo pessoal, incorporando e sendo

incorporado pelo coletivo. do volume de trabalho e das precárias condições de trabalho.

Considerando que os novos ingressantes no quadro da magistratura nacional através de concorridos concursos públicos muitas vezes ainda não dispõem de experiência que sirva de embasamento e suporte para o exercício do ofício de julgador, torna-se urgente o questionamento sobre seu preparo para o exercício da magistratura e o papel que o coletivo de trabalho dos próprios juízes pode exercer nesse caso, levando-se em conta os níveis de tensão e o desgaste próprios ao exercício da função, elevados pelas mudanças e pelos novos atributos que Ihes são conferidos.

\section{A dimensão coletiva do trabalho}

Toda uma linhagem das ciências do trabalho considera que o coletivo de trabalho seja fundamental para o desenvolvimento das competências de quem trabalha, assim como para a construção de sua saúde e identidade (Athayde, 1996; Clot, 2006; Dejours, 1993; Guérin, Laville, Daniellou, Duraffourg, \& Kerguelen, 2005; Leplat, 1994). No caso dos juízes, embora o ato de julgar seja um ato em geral visto como solitário (já que a sentença é proferida por ele individualmente), entendese, neste artigo, que isso não significa que seu trabalho esteja situado em um contexto em que não há outros juízes, no mesmo fórum ou em outros.

Como aponta Athayde, os coletivos de trabalho podem adquirir modos de funcionamento variados, não estando limitados à operação presencial e conjunta na realização de uma tarefa, sendo uma de suas funções a ajuda nas tomadas de decisões, já que as "trocas interindividuais permitem ajudar a resolução individual do problema" (p. 71). Nessa mesma linha, Lhuilier (2006) afirma que "o que é determinante não é a co-presença ou o pertencimento formal, mas a cooperação manifestada e o sentimento de pertencimento que liga cada um aos outros em uma unidade de trabalho" (p. 157).

Defende-se, aqui, junto a Dejours (1993), que "a cooperação é um elemento capital do sucesso da organização do trabalho.... Não há coletivo sem cooperação".

Para que essa cooperação ocorra, segundo aquele autor, é necessário que as maneiras de trabalhar de cada um possam ser conhecidas pelos outros, que sejam visíveis a partir da confiança entre aqueles que trabalham, sendo fundada sobre a ética (regras do ofício) e sobre a racionalidade da ação em relação aos valores morais. Não é, portanto, prescrita ou estabelecida de fora, mas construída pelos próprios membros de um coletivo. Estabelece-se, desse modo, uma retroação entre a formação do coletivo e a cooperação. Forma-se, em consequência, uma visibilidade a partir da qual os pares podem partilhar experiências e oferecer retribuições simbólicas ao trabalho bem realizado por cada um.

A cooperação no coletivo supõe, então, a confiança, elemento indispensável na relação entre pessoas, em que cada uma conhece os princípios éticos que organizam a conduta do outro. Ela se funda na partilha de regras, de princípios de trabalho, pois um coletivo opera em um quadro compartilhado. Para além de um sentimento, algo da ordem psicoafetiva, a confiança remonta à construção de regras, acordos e normas não só técnicas mas também organizadoras de todas as relações sociais. É assim que o ajustamento da organização do trabalho passa pela realização de condições éticas (Athayde, 1996).

Para Clot (2008), o coletivo de trabalho tem uma função primordial na manutenção e no desenvolvimento de um ofício, sendo condição para que alguém consiga realizar 
bem seu trabalho e aperfeiçoar seu estilo pessoal, incorporando e sendo incorporado pelo coletivo. Assim, ao se iniciar em um novo ofício, o ingressante procura realizar o trabalho a partir dos conhecimentos adquiridos durante os treinamentos formais (para os juízes, o curso de Direito e a própria preparação para o concurso), mas percebe que são insuficientes. Nesse momento, o ingressante circula em esferas mais externas do coletivo de trabalho. Ao perceber aquela insuficiência, procura dar novos passos em direção ao núcleo do coletivo profissional, observando os mais experientes para copiar o que fazem, mas percebe novamente que tal estratégia é ainda insuficiente. Começa, desse modo, a incorporar aquele coletivo, mas este ainda se situa como algo que the é externo, que ele precisa, portanto, tentar copiar. Finalmente, o iniciante começa, a partir das trocas mais efetivas com os outros, a compreender as regras próprias daquele meio profissional e a incorporá-las a seu modo. Pode, assim, trabalhar de sua própria maneira, com seu próprio estilo pessoal no interior de um gênero profissional (Clot, 2006, 2008), seguindo e eventualmente modificando as regras daquele coletivo. Nesse momento, quando esse coletivo deixa de ser algo externo para ele, passa a sentir-se e a ser reconhecido como membro do coletivo, já que as regras coletivas de ofício estão também nele, verdadeiramente incorporadas. Ele passa a fazer parte daquele corpo, e isso chega mesmo a modificá-lo corporeamente. Assim, o coletivo de trabalho oferece instrumentos para que cada um supere as dificuldades encontradas no seu meio, servindo de zona de desenvolvimento potencial (Clot, 2006).

Também Zarifian (2001a) marca fortemente o lugar do coletivo no desenvolvimento das competências daqueles que estão em situação de trabalho, afirmando que "a qualidade das interações é, de ora em diante, fundamental para melhorar o desempenho das organizações" (p. 45). Clot reitera que o trabalho coletivo vai além do conjunto de pessoas com quem se trabalha diretamente, já que possui uma história e regras construídas, em parte em outra época e lugar. Zarifian, ao definir o que é competência, apresenta-a também como a faculdade de mobilizar uma rede de atores em torno das mesmas situações, fazendo com que compartilhem as implicações de tais situações e assumam áreas de corresponsabilidade, ou seja, assevera que as pessoas estabelecem suas redes com as pessoas com as quais trabalham e também com outras pessoas de suas redes profissionais e pessoais (Zarifian, 2001b), elemento corroborado junto aos juízes que participaram dessa investigação, como se verá neste artigo.

\section{Método}

Para a pesquisa, fez-se uso de uma abordagem qualitativa, em razão do interesse a uma aproximação das experiências subjetivas dos juízes, buscando com eles decifrar o caráter sempre enigmático do trabalho, pois entende-se aqui que a estratégia dialógica constitui um meio de co-construção de um conhecimento sobre suas vivências do e no trabalho.

Assim, a ferramenta básica nesta pesquisa foi o diálogo, como via privilegiada de acesso à realidade, ao real do trabalho (Dejours, 2007) e ao real da atividade (Clot, 2006). Alinha-se aqui à perspectiva da ergologia (Schwartz \& Durrive, 2007), quando afirma que as pessoas, ao discorrerem sobre suas experiências de trabalho, desvendam relações inusitadas, de tal modo que falar sobre o trabalho é muito mais do que simplesmente descrever a rotina, "é descobrir, é descobri-la por si mesmo, redescobri-la" (p. 179). É por isso que as pessoas, ao falarem sobre o próprio trabalho, podem sobre ele refletir, voltando ao local de trabalho com um olhar diferente sobre sua atividade e sobre a dos colegas. 
Participaram dessa investigação treze juízes do trabalho que atuavam na primeira instância, ou seja, nas Varas do Trabalho, sendo cinco juízes titulares e oito substitutos. Definiu-se como critérios para escolha dos participantes do estudo estar atuando nas Varas da Capital e encontrar-se em efetivo exercício da atividade. A participação de todos os voluntários levou em consideração os aspectos éticos pertinentes à investigação envolvendo seres humanos, conforme a resolução no. 196/96 do Conselho Nacional de Saúde. Apenas após aprovação pelo Comitê de Ética e consentimento dos participantes, foi dado início à pesquisa.

Como instrumento de produção de dados, optou-se pela técnica de entrevista semiestruturada, pois sua flexibilidade favorece um contato mais íntimo entre pesquisador e protagonista do trabalho. Guérin et al. (2005) afirmam que cada resposta a uma determinada questão pode suscitar outras questões não previstas inicialmente, o que pode resultar em uma descrição e reflexão mais precisa e rica.

A estratégia de escolha dos entrevistados foi do tipo bola de neve, na qual um entrevistado indica outro, até que se alcance o nível de saturação. Segundo Minayo (2006), a saturação pode ser operacionalmente definida como a suspensão de inclusão de novos participantes quando os dados obtidos passam a apresentar, na avaliação do pesquisador, certa redundância ou repetição. Assim, a pesquisa teve início com alguns juízes com os quais um dos membros do grupo de pesquisadores possuía algum contato prévio que, por sua vez, se desdobraram em outras indicações até atingir um número que foi julgado adequado.

O trabalho analítico sobre os materiais produzidos foi conduzido por meio do método de análise de conteúdo temática, que, segundo Laville e Dionne (1999), "consiste em desmontar a estrutura e os elementos do conteúdo para esclarecer suas diferentes características e extrair sua significação" (p. 214). O primeiro momento analítico foi, portanto, destinado à organização dos materiais gerados por meio da transcrição das entrevistas, a fim de manejá-las com maior clareza e facilidade ao longo do processo de análise. Posteriormente, fez-se um estudo minucioso de todo o conteúdo, a fim de obter familiarização com o material produzido nas entrevistas. Optou-se pelo recorte de conteúdo a partir de temas, ou seja, foram selecionados fragmentos dos depoimentos de acordo com suas similaridades ou particularidades, e compusemos os chamados núcleos de sentido.

A perspectiva da ergologia (Schwartz \& Mencacci, 2008; Schwartz, 2000; Schwartz \& Durrive, 2007) foi a orientação geral na pesquisa que dá origem a este artigo, seja na sinergia entre o saber profissional dos juízes e o nosso, como pesquisadores sobre o trabalho, seja no uso de diferentes abordagens clínicas do trabalho, como a ergonomia da atividade, a psicopatologia e psicodinâmica do trabalho e a clínica da atividade. Essas abordagens clínicas forneceram não o método, mas a fundamentação teórica utilizada para compreender a vivência subjetiva sobre e no trabalho dos protagonistas do assunto em foco nesta pesquisa.

\section{Resultados}

\section{As dificuldades iniciais de gerir-se na atividade}

Não obstante a grande dificuldade de ingressar na magistratura pela via de disputado concurso público, a simples aprovação nas provas apenas indica que o profissional aspirante ao cargo possui os conhecimentos que foram objeto de avaliação no processo seletivo. Ao iniciar seus trabalhos, no entanto, os juízes 
não se sentem em condições imediatas de assumir os encargos da nova função. Nesse sentido, merecem consideração os relatos a seguir:

\begin{abstract}
Aí passei no estágio probatório, aquela fase muito difícil, que é quando você não conhece nada e não conhece ninguém na área, você sente muita insegurança. Então era muito sofrimento... Eu passei dois anos, como eu te disse, sofrendo! ...Foi um sofrimento! $O$ advogado queria falar mais alto comigo... Mas isso acabei tendo conhecimento com a prática, mesmo.
\end{abstract}

Como se pode apreender da fala anterior, o peso da responsabilidade é sentido tão logo se assume a nova função, conformando o período inicial na função como uma fase de insegurança, medo e dúvida, responsável por um sofrimento psíquico significativo. Percebe-se, no relato, o sentimento de muita insegurança sobre como se portar na sala de audiência, qual o modo mais adequado de inquirir as partes, o que e como perguntar para fazer emergir os elementos não evidentes no processo, e, especialmente, como enfrentar os advogados, às vezes mais experientes que o próprio juiz e prontos para submetê-lo a diversos tipos de testes. Essas parecem ser as maiores ansiedades enfrentadas pelo principiante na magistratura.

Os relatos dão um destaque particular ao receio provocado pelo embate com os advogados. É provável que muitos deles, quando percebem que o juiz é novato no ofício, tentem fazer uso do constrangimento e da intimidação, fragilizando-os psiquicamente como forma de fazer valer seus argumentos e interesses, ou até como meio de testar o preparo e a firmeza do novo juiz na condução do processo. Enfrentar o advogado experiente constitui, então, verdadeira prova de fogo, um batismo na profissão.

Ainda nessa linha, outra dificuldade relatada pelos juízes diz respeito à falta de articulação entre a teoria aprendida durante a formação acadêmica e a prática profissional. O que se aprende na Academia, com os professores e os livros, não corresponde à situação real com a qual se deparam na fase inicial no ofício, conforme se pode apreender das falas seguintes:

Porque, às vezes, tá no livro, mas você não sabe aplicar. Então, foi na marra.

Tem coisas que você vê no livro, o livro te diz exatamente... Você sabe o que é, você sabe como decidir, mas você não sabe como fazer. A gente sai da faculdade com muitas dúvidas. Você aprende a teoria lá. A prática, às vezes, aqui, é muito diferente.

O conhecimento teórico do Direito mostrase, em sua prática, insuficiente para lidar com as diversas situações presentes no trabalho. De fato, a perspectiva ergológica (Schwartz \& Durrive, 2007) nos mostra que a atividade de trabalho apresenta características e dificuldades que são sempre singulares, impossíveis de serem completamente antecipadas em qualquer curso ou livro, em qualquer prescrição.

No trabalho, há sempre o movimento, o inesperado. Por um lado, a presença da atividade de outrem, que se revela no patrimônio de normas antecedentes que estruturam uma determinada situação de trabalho; por outro lado, a atividade de renormatização, operando-se a capacidade de criar novas normas, mesmo que no infinitesimal, mesmo que só parcialmente. Trabalhar sempre constitui um debate de normas e valores, pois, do ponto de vista da atividade, ele é sempre lugar de uma dialética entre um patrimônio recebido que inclui a prescrição e a atividade do sujeito.

No entanto, não há como ignorar a queixa generalizada de estudantes e profissionais sobre o modo como a formação universitária é conduzida, em que a relação entre teoria e prática, mais especificamente entre os pesquisadores/formadores e os práticos, é esporádica. A formação profissional, de 
acordo com Vasconcelos e Lacomblez (2004), é "normalmente concebida por profissionaisespecialistas... muitas vezes sem referência direta à especificidade das situações que visa a atingir" (p. 167).

Jobert (1999) reivindica uma nova postura por parte dos profissionais de formação, que supere a dicotomia teoria-prática dominante na prática educacional para os mundos do trabalho, e que colabore, assim, para reduzir o fosso que separa a Academia, lugar consagrado à produção de conhecimentos, e os mundos do trabalho, lugar do empírico, do prático. Tal incomunicação parece estar na raiz da insatisfação que vários juízes manifestaram no tocante à formação universitária.

Além da insuficiente experiência profissional, outro fator gerador de ansiedades é a falta de experiência de vida dos que ingressam na magistratura ainda muito jovens. Um dos participantes da pesquisa relatou as dificuldades de assumir a atividade judicial com pouca experiência de vida, tendo que decidir sobre questões que requerem vivência e maturidade pessoal:

Sabe como é... aquela coisa... todo mundo resolve todos os seus problemas na sua casa e, de repente, você faz um concurso, você vira juiz e vai decidir a vida das pessoas... Que você não tem nem experiência pra isso. Porque você conhecer o Direito é uma coisa, e você ter experiência pra aliar o Direito à tua experiência pra poder decidir é uma situação diferente, né?... Porque, pra você ser juiz, também você precisa ter maturidade.

Sabe-se, com a ergonomia da atividade (Guérin et al., 2005; Wisner, 2004), que a distância entre o trabalho prescrito e o trabalho real precisa ser gerida, e que toda situação de trabalho é uma confrontação de uma pessoa com características singulares sempre variáveis - nesse caso, sua formação acadêmica e pessoal - com objetivos e meios, igualmente variáveis, previamente estabelecidos pela organização do trabalho.

Frente à complexidade das situações e à pouca experiência do juiz, acaba cada um isoladamente - tentando gerir as dificuldades que se lhes apresentam a partir de suas próprias características e valores, a fim de dar conta dos desafios concretos que se apresentam no curso do trabalho. Concorda-se aqui com a perspectiva da ergologia, que mostra, na linhagem de Canguilhem (1947/2001), que toda atividade de trabalho tenta encontrar um núcleo de renormatização, ou seja, que em toda atividade de trabalho há uma tentativa da pessoa de ajustar o meio às suas próprias normas, mesmo que no ínfimo, mesmo que parcialmente recentrando o meio.

No que diz respeito especificamente ao ato profissional de julgar, este requer não só a aquisição de conhecimentos técnicojurídicos das leis e regras processuais mas também, e principalmente, a capacidade de sensibilidade, experiência e reflexão, além de uma sólida base conceitual, um conjunto que permita julgar/decidir com firmeza e agilidade.

É nesse sentido que maior proximidade com o mundo do trabalho jurídico por meio da reflexão coletiva sobre o que nele acontece, sobre os valores que presidem as suas decisões, pode se revelar mais favorável à constituição de uma base ética (de regras de trabalho e valores), importante para a atuação como magistrado. Nesse sentido, o pertencimento a um coletivo de trabalho poderia suprir essa falta, favorecendo o desenvolvimento das competências requeridas pelas novas situações.

A esse respeito, Zarifian (2001a) assume a posição - tendo como referência as mudanças recentes (tecnológicas/organizacionais) nos mundos do trabalho - de que a competência profissional está hoje muito mais relacionada 
ao que ele nomeia "eventos", à variedade das situações enfrentadas, do que à antiguidade no posto de trabalho. Desse modo, quanto maior a variedade de eventos já enfrentados, maiores as possibilidades de aprendizagem e de desenvolvimento, o que contraria a ideia arraigada que postula uma relação de causalidade entre tempo de atuação, experiência e qualidade da ação. A juvenilidade, nesse raciocínio, não seria necessariamente um empecilho à aquisição de competências profissionais desde que devidamente apoiada, no período clássico de formação e também ao longo do exercício profissional, por dispositivos reflexivos, que promovessem o diálogo crítico e sinérgico entre os profissionais do conceito (formadores/pesquisadores) e os protagonistas do trabalho, potencializando e desenvolvendo a atuação de ambos. Para tanto, a organização do trabalho deve destinar tempo a esse exercício reflexivo sobre as situações de trabalho, conferindo um caráter qualificante (no curso da ação laboral) à organização (pois que qualificada ela já o é, considerando o caráter criterioso dos concursos públicos).

A pesquisa revelou que nenhum dos entrevistados havia participado de cursos de formação no exercício da magistratura. A análise das entrevistas revelou também que, na falta de uma preparação formal, restou aos juízes (sem um debate sistemático em um coletivo profissional) aprender na própria lida diária, no fazer das audiências, na elaboração das sentenças, nos despachos efetuados, na inquirição dos fatos, enfim, nas atividades com as quais se deparam no dia a dia:

A gente aprende, mesmo, trabalhando. Não tem como o juiz entrar na magistratura preparado como juiz. Isso é besteira! Nenhum candidato, quando entra na magistratura, senta na cadeira no primeiro dia preparado para ser juiz. Ele tem a preparação intelectual, tem o conteúdo na cabeça, tem as matérias que precisa, tem os elementos. Mas a atividade da magistratura, mesmo, só no dia a dia, só aprendendo, lidando, vendo os percalços, os obstáculos.

É certo que, sem desconsiderar a importância da prática teórica, é na prática técnica que vai ocorrer a efetiva aprendizagem e o desenvolvimento de qualquer ofício. A formação escolar busca dar conta dessa complexidade através da figura do estágio supervisionado, necessário, mas não suficiente, exigindo o funcionamento do coletivo de trabalho como um supervisor coletivo permanente ao longo da vida profissional, garantindo a continuidade e o desenvolvimento do gênero profissional (Clot, 2006). Aqui se retoma Dejours (2007), quando lembra que o trabalho supõe o uso de habilidades tácitas, que formam o que esse autor conceitua por inteligência corporal, da prática, desenvolvida no próprio curso do trabalho, que permite ao sujeito trabalhar com maior domínio daquele meio, daquele gênero profissional, compreendendo (aprendendo, desenvolvendo ao intervir) suas regras reais de funcionamento. Assim, a realização da atividade de trabalho supõe o uso e o desenvolvimento de uma inteligência da prática que se aperfeiçoa exatamente na realização do próprio trabalho. Essa inteligência faz uso de habilidades tácitas, é dirigida pela experiência e pelos sentidos (é corporal), antecipa-se à simbolização e à consciência, é astuciosa. Os juízes com quem se realizou esta pesquisa sentiram grandemente, ao ingressarem na carreira, a falta de maior desenvolvimento dessa inteligência, de acesso impossível enquanto neófitos, o que lhes trouxe grande sofrimento.

\section{Aprendendo no dia a dia com o coletivo de trabalho}

O ato de aprender com a prática (e de nela apreender a complexidade das coisas da vida e da profissão) pode constituir fator gerador de inseguranças, dúvidas e receios ao aprendiz. Pelo que se investigou, na falta de 
um apoio de engajamento e desenvolvimento profissional sistemático e institucionalizado, a tática usada pelo neófito é recorrer informalmente aos colegas mais antigos na profissão.

Nesse sentido, a pesquisa permitiu perceber que grande parte da transmissão de conhecimentos para o juiz iniciante fica a cargo de juízes mais experientes, especialmente os titulares, mas na ausência de um dispositivo qualificado e qualificante para todos. Recorrer à colaboração de colegas mais antigos na profissão, especialmente daqueles com quem se tem mais aproximação ou afinidade, parece ser prática corrente que ajuda a aliviar a insegurança e a ansiedade decorrentes do risco de erro por falta de experiência. Como já foi pontuado, o coletivo de trabalho tem historicamente uma função primordial no trabalho, na manutenção e no desenvolvimento de um ofício, sendo imprescindível para todos os seus membros (Athayde, 1996), em especial ao novato, para que consiga realizar bem seu trabalho e desenvolver seu estilo pessoal (Clot, 2008; Dejours, 1993; Zarifian, 2001a). Desse modo, o juiz poderia mais facilmente adquirir maior autonomia, de forma não solitária ou precária, mas que se viabilizaria pelo coletivo de trabalho de forma sistemática.

$\mathrm{Na}$ busca de construir coletivos, dentro e fora do ambiente de trabalho, um recurso utilizado pelos juízes para se manterem atualizados é a discussão de matérias jurídicas com colegas da magistratura e com familiares com formação em Direito. Mobilizam, assim, as redes a que já pertencem de modo a desenvolver suas competências (Zarifian, 2001b). Cabe, entretanto, assinalar uma das limitações dessa tática em curso: a troca de ideias é viabilizada apenas com aqueles com os quais se possui muita afinidade, conforme demonstra o depoimento a seguir: "Eu acho que não existe isso (esclarecer dúvidas relacionados ao trabalho) com todos os colegas, mas com aqueles que você tem mais afinidade".

Conversar com os pares sobre determinadas matérias jurídicas certamente pode ser um modo eficiente de aquisição de conhecimentos e de desenvolvimento profissional. Entretanto, a condição para que esse intercâmbio se efetive é a relação de afinidade estabelecida com o colega. Assumir as dúvidas e a falta de informação sobre determinado assunto jurídico implica correr riscos, pois, ao se expor ao outro, se sujeita, inclusive, a seu julgamento e recriminações: "Tu vai perguntar pra um colega, primeiro ele te dá uma aula, e ainda pergunta: 'Mas tu não sabe isso?' Aí já intimida!"

Para que se estabeleça esse espaço de contato entre os pares que funcione como suporte social para o diálogo crítico e formador, é preciso, antes, que se estabeleçam relações de confiança e de acolhimento, favorecendo um ambiente adequado à possibilidade de desenvolvimento, algo que, a partir de Vigotski, Clot (2006) denomina "zona de desenvolvimento potencial". Trata-se de colocar a ética como cimento para construir espaços de cooperação (Dejours, 1993). Como mostra Zarifian (2001a), comunicar é criar laços de compreensão que vão muito além da simples informação, mas que supõem campos de entendimentos recíprocos.

No caso dos magistrados, no entanto, o atual modo de funcionamento do Judiciário não favorece o desenvolvimento das competências do novato, já que cada juiz trabalha sozinho e que recai sobre ele uma imagem socialmente construída, ainda que em transformação, de que o juiz, para ser o guardião da lei, deve ser uma pessoa com muitos poderes, senhor de si e quase super-humano. Diante desse quadro, ele acaba tendo que construir suas competências, em geral, contando, sobretudo, com alguns outros juízes e com pessoas de sua relação pessoal, fora da magistratura, o que torna esse processo precário, lento e sofrido. 
As práticas de formação continuada

Por ser reconhecidamente importante o contínuo aperfeiçoamento profissional para quem exerce a função de julgador, que necessita acompanhar e estar sempre atento às transformações sociais e aos avanços do Direito, a Constituição Federal (1988) define, no artigo 93, como um dos critérios para promoção por merecimento do juiz, a frequência e o aproveitamento em cursos oficiais ou de aperfeiçoamento, devidamente reconhecidos.

A atuação do magistrado requer permanente atualização, já que o Direito é uma disciplina em constante atualização, o que impõe estudos constantes. Conforme frisaram alguns entrevistados, na condição de julgadores, não há como desconsiderar a busca de novos conhecimentos, sendo a própria atividade um modo de aprendizagem, pois cada processo a ser julgado é singular e impõe ao magistrado o domínio da legislação, o que, por sua vez, implica constante revisão de conteúdos e aquisição de outros tantos:

A gente tá sempre se atualizando, né? A própria legislação não nos deixa assim acomodados, porque tá tendo sempre alterações, e isso a gente faz dentro do trabalho, se envolvendo com o trabalho, né?... O próprio trabalho te impõe, não tem como, tem que buscar. $E$, quanto mais você julga uma matéria, mais você se atualiza, mais você fica sabendo como lidar com aquele assunto.

Por meio dos relatos, os juízes indicaram como principais entidades patrocinadoras de aperfeiçoamento profissional o próprio Tribunal e a Associação dos Magistrados Trabalhistas (AMATRA). Esses organismos promovem, eventualmente, cursos, palestras, congressos e outros eventos de capacitação e atualização para os magistrados, sobretudo quando há alguma reforma constitucional ou alterações que se reflitam diretamente em suas atividades.
Entretanto, embora já se vislumbre nessas duas instituições um movimento no sentido de promoção de cursos de capacitação para os magistrados, estes foram considerados pelos participantes ocasiões raras ou incipientes, que não atendiam plenamente às necessidades de atualização dos juízes que atuam no Tribunal onde o estudo se realizou, sendo inclusive mencionado como empecilho à sua participação a inconveniência dos horários de realização dos eventos.

Percebe-se que, na falta de maior e mais estruturado dispositivo institucional e sistemático de desenvolvimento, a busca pelo aprimoramento profissional se dá mais em caráter pessoal, individualizado, logo, precário, o que é certamente fonte de inseguranças e ansiedades, gerando dificuldades quando o juiz não pode contar com um coletivo que o apóie em seu dia a dia (Clot, 2008).

A maioria fez referência à leitura frequente e intensa de livros e periódicos como um dos meios mais eficazes de atualização, sendo citada, também, a pesquisa na internet, especialmente em sites especializados, tais como os do Tribunal Superior do Trabalho, do Supremo Tribunal Federal, do Supremo Tribunal de Justiça e dos outros Tribunais Regionais.

A realização de cursos, no entanto, mostra-se muitas vezes dificultosa, não só pelos horários como também pelo excesso de trabalho dos magistrados. De fato, um dos aspectos mais problemáticos do Poder Judiciário é o aumento considerável na quantidade de litígios, sem que o número de juízes tenha crescido proporcionalmente. Para dar conta do volume de trabalho, não é raro levar trabalho para casa, conforme evidenciado pela pesquisa. A esse respeito, Zarifian (1998) afirma que os trabalhadores, em geral, 
respondem de forma positiva ao aumento das responsabilidades (como o que aconteceu com os juízes do trabalho em função da promulgação da Emenda Constitucional no 45), porém, o que ocorre é que esse acréscimo de responsabilidades se dá sem os meios necessários para tal, tais como pessoal, meios técnicos e informações, entre outros.

Outro aspecto citado pelos participantes como impeditivo para uma atualização mais efetiva é a localização geográfica daquele Tribunal onde se realizou a pesquisa. Nesse sentido, um dos entrevistados fez a seguinte observação:

Mas aquela atualização institucional, no sentido de participação em seminários, em congressos, em encontros, essa aí fica um pouco prejudicada, por conta da nossa distância geográfica do centro do País... porque o deslocamento é caro, os custos de manutenção, fora do local, também são caros, o que dificulta um pouco essa atualização... A distância geográfica é um fator impeditivo, sim, de uma atualização mais concreta, mais densa, mais substancial do juiz.

Assim, a localização geográfica dos Tribunais localizados no norte do País é uma das particularidades que gera dificuldades específicas no dia a dia desses juízes. A distância e a inexistência de estradas ligando a maioria dos Municípios ao restante do País são, certamente, fatores que representam obstáculos à participação em cursos realizados em outras localidades, dificultando, também, a promoção de eventos mais vultosos no próprio Município, os quais pudessem contar, por exemplo, com a participação de personalidades de destaque na área jurídica e de magistrados que atuam em outros regionais. Eventos dessa natureza certamente contribuiriam para a ampliação de conhecimentos, a troca de experiências, o incentivo à inovação e o despertar da criatividade.
A Lei Orgânica da Magistratura Nacional (LOMAN) concede ao magistrado o direito ao afastamento de suas funções para a participação em cursos ou seminários de aperfeiçoamento e estudo, pelo prazo máximo de dois anos, sem prejuízo de seus vencimentos e vantagens, ficando a referida liberação a critério do Tribunal. Contudo, um dos entrevistados, referindo-se ao aludido direito, posicionou-se da seguinte forma:

Hoje os juízes que estão aí estão, realmente, trabalhando no limite mesmo. Então é, talvez, da minha parte, excesso de responsabilidade, de ver o que está acontecendo, de ver quantas pessoas estão precisando que seus processos sejam julgados, que eu não me dei ao privilégio de fazer curso. De, pelo menos, parar e dizer: vou fazer isso, agora é a minha vez. Mas eu até já suspendi períodos de férias pra poder continuar... pra cobrir a Vara, imagina pra fazer um curso!

Como se pode perceber, a prerrogativa formal de afastamento para participação em cursos, principalmente em nível de pós-graduação, é considerada muitas vezes como um direito do qual nem sempre se pode usufruir, em razão do volume de trabalho.

\section{Considerações finais}

A entrada em qualquer grupo laboral supõe do iniciante um esforço para apreender as normas de funcionamento que regulam as atividades ali desenvolvidas, mais ainda as formas de renormatizações singulares. Como aponta Schwartz (Schwartz \& Durrive, 2007), é a partir da apropriação dessas regras que o novato conseguirá colocar aquelas normas em debate com as suas próprias e incorporar as elaborações que aquele grupo e outros da mesma categoria construíram, assim como contribuir para o aprimoramento desses saberes e práticas. O conhecimento teórico, anterior à experiência de cada um 
àquelas situações de trabalho, é sempre insuficiente, pois o meio precisa sempre ser gerido frente aos desafios das variabilidades. Esse é um processo que pode ser doloroso, mas que pode permitir o desenvolvimento das competências pessoais e o avanço da humanidade em caminhos até então nunca percorridos.

Apesar da solidão em que normalmente trabalham os juízes, herdeiros de uma visão socialmente reforçada de que são pessoas sempre muito poderosas e seguras, para os juízes novatos, a proximidade com outros mais antigos em um possível coletivo de trabalho é o que poderia tornar menos sofrido (inclusive patogenicamente) o desenvolvimento das competências de que necessitam em seu dia a dia de trabalho. No entanto, como já foi dito, a atual organização do trabalho no Judiciário, a estrutura e o papel deste enquanto garantidor do cumprimento das normas legais, poder soberano da União, leva o juiz a uma situação de grande solidão no trabalho, dificultando a cooperação entre eles. Essa dificuldade de criação de condições de cooperar cria entraves para o desenvolvimento profissional dos juízes, já que é a cooperação que funda um coletivo de trabalho (Dejours, 1993). Tal quadro deixa seus membros em situação de grande solidão não apenas no momento do julgamento, mas também fora, nas diversas situações em seu dia a dia.

O sentimento de despreparo do novato na magistratura se deve, principalmente, à falta de articulação entre a teoria aprendida na formação acadêmica (inclusive nos estágios supervisionados) e as situações vivenciadas na prática da magistratura, além da ainda pouca vivência de vida e maturidade pessoal para aqueles que brilhantemente passam nos concursos, mas que começam a trabalhar ainda com pouca experiência profissional e de vida na função. Para além da necessidade da formação de laços (cognitivos, afetivos e sociais) entre os juízes que permitiriam um início da carreira menos sofrido, considera-se, como fruto desta pesquisa, imprescindível o investimento em sua formação continuada, seu desenvolvimento, estratégia que teria nos coletivos de trabalho seu eixo principal. Nesse sentido, eles se encontram em grande e crescente dificuldade em face da crescente intensificação de seu trabalho, que impede suas ausências inclusive para formas já clássicas de formação, como as de cursos que, embora limitados, poderiam levar mais em conta o trabalho real dos juízes, suas atividades, seus conhecimentos e suas limitações, em um processo de verdadeira formação para o trabalho, para o seu desenvolvimento.

Em uma sociedade em transformação, em que padrões, normativas e valores são constantemente reformulados, o juiz enfrenta situações inusitadas que, na sua lida diária, assumem feições e nuances diferenciadas daquelas concebidas na formação acadêmica, colocando-se em evidência a necessidade de uma formação especializada da magistratura. 
Genilza Evaristo Machado

Mestre em Psicologia Social pela Universidade Federal da Paraíba, Paraíba - PB - Brasil.

\section{Anísio José da Silva Araújo \\ Doutor em Ciências}

E-mail: anisiojsa@uol.com.br

Paulo César Zambroni-de-Souza

Doutor em Psicologia Social

E-mail: paulozamsouza@yahoo.com.br

Milton Raimundo Cidreira de Athayde

Doutor em Engenharia de Produção/Ergonomia

E-mail: athayde.milton@gmail.com

* Endereço para envio de correspondência:

Universidade Federal da Paraíba - UFPB Departamento de Psicologia

Cidade Universitária - Campus I João Pessoa - PB - Brasil CEP: 58059-900

E-mail: genilzaem@ig.com.br

Recebido 26/6/2009, Aprovado 22/9/2009.

\section{Referências}

Athayde, M. (1996). Gestão de coletivos de trabalho e modernidade: questões para a engenharia de produção. Tese de Doutorado em Engenharia de Produção - COPPE, Universidade Federal do Rio de Janeiro, Rio de Janeiro, RJ.

Brasil. (1988). Constituição da República Federativa do Brasil de 1988. Recuperado em 25 de maio de 2009, de http://www. planalto.gov.br/ccivil_03/constituicao/constitui\%C3\%A7ao. htm

Brasil. (2004). Emenda Constitucional $n^{\circ} 45$, de 31 de dezembro de 2004. Recuperado em 25 de maio de 2009, de http:// www.planalto.gov.br/ccivil_03/constituicao/Emendas/Emc/ emc45.htm

Canguilhem, G. (2001). Meio e normas do homem no trabalho. Pro-posições, 12(2-3), 109-121. (Trabalho original publicado em 1947)

Clot, Y. (2006). A função psicológica do trabalho. Petrópolis, RJ: Vozes.

Clot, Y. (2008). Travail et pouvoir d'agir. Paris: PUF.

Dejours, C. (1992). A loucura do trabalho: estudo de psicopatologia do trabalho. São Paulo: Cortez.

Dejours, C. (1993). Coopération et contruction de l'identité en situation de travail. Recuperado em 14 de abril de 2009, de http://multitudes.samizdat.net/Cooperation-et-constructionde-l

Dejours, C. (2007). O fator humano. Rio de Janeiro: FGV.

Guérin, F., Laville, A., Daniellou, F., Duraffourg, J., \& Kerguelen, A. (2005). Compreender o trabalho para transformá-lo: a prática da ergonomia. São Paulo: Edgard Blücher.

Jobert, G. (1999). A inteligência no trabalho. In P. Carré \& P. Caspar (Eds.), Tratado das ciências e das técnicas da formação. Lisboa: Instituto Piaget.

Laville, C., Dionne, J. (1999). A construção do saber: manual de metodologia da pesquisa em ciências humanas. Porto Alegre: Ed. da UFMG.

Leplat, J. (1994). Colletive activity in work. Some ways of research. Le Travail Humain, 57(3), 209-226.

Lhuilier, D. (2006). Cliniques du travail. Paris: Erès.
Minayo, M. C. de S. (2006). O desafio do conhecimento: pesquisa qualitativa em saúde. São Paulo: Hucitec.

Prado, L. R. A. (2005). O juiz e a emoção: aspectos da lógica judicial (3a ed.). Campinas, SP: Millennium.

Ribeiro, H. P. (2005). O juiz sem a toga: um estudo da percepção dos juízes sobre trabalho, saúde e democracia no Judiciário. Florianópolis: Lagoa.

Sadek, M. T. (2006). Magistrados: uma imagem em movimento. In M. T. Sadek, S. A. Beneti \& J. Falcão, Magistrados: uma imagem em movimento. Rio de Janeiro: FGV.

Schiavi, M. (2006). O alcance da expressão "relação de trabalho" e a competência da Justiça do Trabalho um ano após a promulgação da EC no $45 / 04$. Revista do Tribunal Superior do Trabalho, 72(1), 36-59.

Schwartz, Y. (2000). Le paradigme ergologique ou un métier de philosophe. Toulouse: Octarès.

Schwartz, Y., \& Mencacci, N. (janeiro/junho, 2008). Trajectoire ergologique et genèse du concept d'usage de soi. Informática na Educação: Teoria \& Prática, 11, 1.

Schwartz, Y., \& Durrive, L. (Eds). (2007). Trabalho e ergologia: conversas sobre a atividade humana. Niterói, RJ: Ed. da Universidade Federal Fluminense.

Vasconcelos, R., \& Lacomblez, M. (2004). Entre a auto-análise do trabalho e o trabalho de auto-análise: desenvolvimento para a psicologia do trabalho a partir da promoção da segurança e saúde no trabalho. In M. Figueiredo, M. Athayde, J. Brito \& D. Alvarez (Eds.), Labirintos do trabalho: interrogações e olhares sobre o trabalho vivo. Rio de Janeiro: DP\&A.

Wisner, A. (2004). Textos escolhidos: antropologia. Rio de Janeiro: EVC.

Zarifian, P. (1998). A gestão da e pela competência. In Anais do Seminário Internacional Educação Profissional, Trabalho e Competências (pp. 15-24). Rio de Janeiro: CIET.

Zarifian, P. (2001a). Objetivo competência: por uma nova lógica. São Paulo: Atlas.

Zarifian, P. (2001b). Mutação dos sistemas produtivos e competências profissionais: a produção industrial de serviço. In M. Salerno (Ed.), Relação de serviço: produção e avaliação. São Paulo: SENAC. 